\title{
LEI 13.491/2017: UMA QUESTÃO DE RETROCESSO DEMOCRÁTICO, DIREITOS E GARANTIAS FUNDAMENTAIS E AMPLIAÇÃO DA COMPETÊNCIA DA JUSTIÇA CASTRENSE
}

\author{
Rafaela Cândida Tavares Costa ${ }^{1}$
}

\section{RESUMO}

O estudo analisará a Lei n. 13.491/2017, que modificou o artigo 9o do Decreto-Lei n. 1.001/1969, aumentando a competência da Justiça Militar da União, seguindo tendência oposta da maioria de outros ordenamentos internacionais. A fim de analisar o problema proposto, a pesquisa será desenvolvida adotando-se como referencial teórico o artigo: Lei $13.491 / 2017 \mathrm{fez}$ muito mais do que retirar os militares do tribunal do júri. A pesquisa adotou como procedimento a análise documental e a revisão bibliográfica, e como método de inferência, o dedutivo. Com relação aos resultados percebeu-se um retrocesso democrático e uma restrição de direitos e garantias fundamentais.

Palavras-chave: Tribunal do Júri; Justiça Castrense; Retrocesso; Direitos e Garantias Fundamentais; Crimes contra a vida.

\section{LAW 13.491 / 2017: A QUESTION OF DEMOCRATIC RETRESS, FUNDAMENTAL RIGHTS AND GUARANTEES, AND EXTENSION OF THE JURISDICTION OF CASTRENE JUSTICE}

\begin{abstract}
The study will analyze the law n. 13.491/2017, which amended article 9 of Decree-Law n. 1.001/1969, increasing the competence of the Military Justice of the Union, following the opposite tendency of international order. To analyze the proposed problem, the research will be developed adopting as theoretical reference the article: Law 13.491 / 2017 did much more than withdraw the military from the jury court. The research adopted as a procedure the documentary analysis and the bibliographic review, and as a method of inference: deductive. As results, was perceived a democratic backward movement and a restriction of fundamental rights and guarantees.
\end{abstract}

Keywords: Court of the Jury; Military Justice; Backspace; Fundamental Rights and Guarantees; Crimes against life.

\section{INTRODUÇÃO}

O Júri Popular possui competência atribuída pela Constituição da República Federativa do Brasil de 1988 para processar e julgar os crimes dolosos contra a vida elencados

\footnotetext{
1 Pós-graduação stricto sensu em Proteção dos Direitos Fundamentais pela Universidade de Itaúna. Pósgraduação lato senso em Direito Notarial e Registral pela Faculdade Damásio. Advogada. E-mail: rafaelacandida@live.com.
} 
nos primeiros artigos da parte especial do Código Penal de 1940, tanto na modalidade tentada, quanto na modalidade consumada. Neste procedimento, a sociedade, através dos jurados, ora juízes do feito, ou de fato, assume a competência para decidir o destino daquele submetido a julgamento.

É um procedimento que possui um viés democrático, pelo menos em tese, a medida que permite que a sociedade determine o destino no autor, sem sequer explicitar os motivos pelos quais os jurados chegaram à conclusão de culpa ou inocência. É ainda, uma garantia e um direito fundamental. Todavia, em 13 de Outubro de 2017, uma novidade fora recebida com certa perplexidade pela comunidade jurídica, ao ponto de ser tratada como um sinal de retrocesso, afetando o direito fundamental ao julgamento pelo tribunal do júri, em determinados casos. A Lei n. 13.491/2017, que modificou a redação do artigo 9 o do DecretoLei n. 1.001, de 21 de outubro de 1969 - Código Penal Militar -, atribuiu à Justiça Militar da União a competência para o julgamento de integrante das Forças Armadas, quando do cometimento de crime doloso, tentado ou consumado, contra a vida de civil, em determinadas ocasiões. A nova lei 'inovou' ainda, quando atribui à Justiça Militar, seja ela federal ou estadual, a competência para o julgamento dos crimes previstos no Código Penal Militar e nas legislações penais comum e especial se praticados por militares.

É sobre esta ampliação de competência da justiça castrense, que vai de encontro, inclusive, com uma tendência de esvaziamento da jurisdição militar, que versa a presente pesquisa. Bem como, se a promulgação da referida lei fere, ou não, direitos e garantias fundamentais.

Apresentado o tema da pesquisa, passa-se à problemática que permeia o trabalho, qual seja: se é válida e viável esta modificação de competência prevista pela Lei n. 13.491/2017, na medida em que esvazia uma competência constitucionalmente assegurada, quando ocorrer o cometimento de crimes dolosos, tentados ou consumados, contra à vida.

O estudo tem como hipótese de que a promulgação da lei supramencionada fere direitos e garantias fundamentais, simbolizando ainda, um retrocesso legislativo. Outro reflexo refere-se à possível mora processual e o aumento da impunidade decorrente do corporativismo da instituição, que não teria condições, em pequeno e médio prazo, de se organizar para julgar estes novos processos.

O trabalho é resultado de uma pesquisa que adotou como procedimento a análise documental - principalmente a Lei n. 13.491, de 2017, que alterou o Decreto Lei n. 1.001, de 21 de outubro de 1969, Constituição da República Federativa do Brasil de 1988, Decreto-Lei 
n. 1.001 (Código Penal Militar), Decreto-Lei n. 1.002 (Código de Processo Penal Militar), Decreto-Lei n. 2.848 (Código Penal), e Decreto-Lei n. 3.689, (Código de Processo Penal) - e o procedimento de revisão bibliográfica, seja através de livros afetos à temática, bem como artigos, principalmente aquele utilizado como marcos-teóricos: "Lei 13.491/2017 fez muito mais do que retirar os militares do tribunal do júri”, de Aury Lópes. Utilizou-se como procedimento metodológico o método dedutivo, partindo de uma concepção macro analítica, para depois chegar-se a um estudo mais específico.

Estruturalmente, o estudo está dividido em três seções temáticas, além de introdução e conclusão. Na primeira seção, intitulada Tribunal do Júri - competências e críticas, que vem logo após esta introdução, será estudado o instituto do Tribunal do Júri como uma garantia constitucionalmente prevista, os princípios inerentes a este procedimento, o papel dos juízes de fato e serão ainda, tecidas algumas críticas.

Por sua vez, na seção seguinte, denominada de Concurso entre a competência do júri e demais órgãos de jurisdição comum e especial, abordar-se-á quando o julgamento pelo Tribunal do Júri prevalecerá, quando ocorrer um conflito aparente de competência entre este procedimento e demais órgãos, seja da justiça especial ou da justiça comum.

Na última seção temática, que possui o título Lei n. 13.491/2017: a ampliação de competência da justiça castrense, uma questão de garantias fundamentais e retrocesso, adentra-se nos objetivos específicos da pesquisa, analisando o aumento de competência da Justiça Militar da União, quando militares federais, pertencentes às forças armadas, cometerem cries dolosos contra a vida de civis, modificação esta que, surge, justamente, quando há um aumento da militarização das polícias, principalmente da polícia administrativa, responsável pelo policiamento ostensivo. Num senário de aumento das “missões de garantia da lei e da ordem”, surge uma diferenciação trazida pela lei em análise, entre militares estaduais e federais. Outro ponto a ser analisado neste tópico refere-se também à ampliação da competência da Justiça Militar, sendo esta federal ou estadual, para o julgamento dos crimes previstos no Código Penal Militar e nas legislações penais comum e especial quando praticados por militares, pertencentes às Forças Armadas ou estaduais. Em seguida, é tecida são tecidas as conclusões e demonstradas as referências utilizadas no presente estudo.

No que se refere ao ponto de vista da abordagem do problema, a pesquisa é do tipo qualitativa, preocupando-se com o aprofundamento da compreensão do objeto de estudo. $\mathrm{O}$ objetivo geral do estudo é analisar competência do Tribunal do Júri. Por sua vez, os objetivos 
específicos são estudar os impactos trazidos pela Lei 13.491 de outubro de 2017, que modificou a redação do artigo 9 o do Decreto-Lei no 1.001, de 21 de outubro de 1969 Código Penal Militar -, atribuindo à Justiça Militar da União a competência para o julgamento de integrante das Forças Armadas, quando do cometimento de crime doloso, tentado ou consumado, contra a vida de civil, em determinadas ocasiões, inovando ainda, ao atribuir à Justiça Militar, seja ela federal ou estadual, a competência para o julgamento dos crimes previstos no Código Penal Militar e nas legislações penais comum e especial se praticados por militares; bem como os reflexos oriundos da promulgação do diploma mencionado.

Deste modo, o estudo versa sobre garantias fundamentais, fazendo uma reflexão acerca dos mecanismos previstos na Constituição da República Federativa do Brasil de 1988 e demais leis, para a defesa de direitos, analisando ainda, a existência de meios processuais adequados e inadequados para a defesa destes.

\section{II - TRIBUNAL DO JÚRI - COMPETÊNCIA E CRÍTICAS}

A competência do Tribunal do Júri é constitucionalmente atribuída. Em homenagem ao princípio da vedação ao juízo ou tribunal de exceção, é reconhecida a competência do Júri Popular, segundo o artigo $5^{\circ}$, inciso XXXVIII, para o julgamento dos crimes contra a vida, na modalidade dolosa, tentados ou consumados. Estes crimes são estabelecidos na parte especial do Código Penal, em seu Título I, dos crimes contra a pessoa, capítulo I, dos crimes contra a vida; e são eles, o homicídio, em sua forma simples ou qualificada; induzimento, instigação ou auxílio a suicídio; infanticídio; aborto provocado pela gestante ou com seu consentimento; aborto provocado por terceiro e, recentemente, incluído através da Lei 13.104 de 2015, o feminicídio. Cumpre mencionar ainda, que vigora no procedimento do Tribunal do Júri, os princípios da plenitude de defesa, sigilo das votações e soberania dos veredictos.

No Júri também é observada a máxima in dubio pro societate, diferentemente do que ocorre na maioria dos procedimentos penais que são regidos pela máxima in dubio pro reo. Significa que os juízes do feito, mesmo que não tenham a certeza dos fatos, mas estando convencidos intimamente da materialidade do episódio e da existência de indícios da autoria ou participação, poderão condenar o acusado. Lembrando que o juiz togado, na decisão de pronúncia, observará o princípio da decisão motivada, que é mandamento de todo e qualquer Estado Democrático de Direito. 
Os juízes do fato atuam como a própria sociedade, decidindo pela condenação, ou não, do acusado. Este veredicto, como já mencionado, deverá ser respeito, com exceção de condenação contrária a prova robusta constante nos autos. Seria então, o Tribunal do Júri, um mecanismo - ou tentativa - de democratização do julgamento, provocando um sentimento maior de reparação, haja vista a maneira como é conduzida o procedimento.

\begin{abstract}
A formação histórica do tribunal do júri decorre do interesse em democratizar os julgamentos. Traz, em seu bojo, uma forte influência religiosa, especificamente cristã, centrada na ideia de justiça decorrente de decisões proferidas pelos jurados de acordo com a sua consciência, ou seja, independente de qualquer fundamentação ou motivação jurídica. Assim, a consciência dos jurados, produto de suas crenças e de suas convicções pessoais, bem como o caráter sacro dos julgamentos ocorridos em um espaço composto por pessoas supostamente preparadas para distribuir e garantir a justiça entre os homens representa alguns dos traços característicos e marcantes do tribunal do júri. (COSTA, 2012, p. 142).
\end{abstract}

Vale ressaltar que, diferentemente do que ocorre em outros procedimentos especiais, em que as decisões proferidas pelo Juiz deverão ser motivadas, prevalece no Tribunal do Júri, o princípio da íntima convicção, como também já fora mencionado.

De acordo com esse sistema, o Juiz não estava obrigado a exteriorizar as razões que o levaram a proferir a sentença; atribuía às provas o valor que em quisesse e entendesse, podendo, até, valer-se do conhecimento extra-autos, mesmo sem nenhuma prova nos autos; decidia de acordo com a sua íntima convicção, sem se deixar dominar pelo que havia no processo. (TOURINHO FILHO, 2010, p. 522).

O princípio da íntima convicção é a prerrogativa inerente ao juiz do fato de valorar as provas, dizeres e julgar o acusado conforme suas próprias convicções, advindas estas da sua cultura, religião ou sociedade em que está inserido. A decisão dos juízes no procedimento do Júri não necessita de fundamentação ou amparo legal. Por isto, é possível que uma pessoa acusada de homicídio, mesmo admitindo o crime e com provas contrárias a este, seja inocentada quando for um crime socialmente justificável, por exemplo, um pai que mata o estuprador de sua filha. Outro ponto refere-se à forma com que cada sociedade, encara um determinado crime. Ou seja, a prática de determinado ato não é vista da mesma forma por pessoas de regiões, estados ou cidades diferentes, da mesma forma que uma pessoa que mora no interior de um estado, convocada como jurada, não possui as mesmas convicções que uma pessoa que mora na capital deste mesmo estado. Por isto o Tribunal do Júri é alvo de severas críticas, como o fez Fabrício V. Costa (2012), que assemelha o procedimento em análise, a um mito democrático. Outro complicador advindo da íntima convicção perfaz no fato de esta 
ser baseada do processo inquisitivo, e não no processo acusatório que é, ao menos em tese, mais democrático.

Os grandes problemas que se vislumbram no sistema inquisitorial são os seguintes: a) concentração das funções de julgar nas mãos do juiz; b) a valoração e a interpretação das provas produzidas por meio de juízos axiologizantes centrados na autoridade do julgador; c) a liberdade de o magistrado determinar, ex officio, a produção de provas suficientes à formação do seu convencimento; d) a dispensa da fundamentação das decisões judiciais, especificamente na atuação dos jurados, que proferirão seus julgamentos de acordo com sua íntima convicção. (COSTA, 2012, p. 147-148).

Um processo penal inquisitivo segue na contramão do Estado Democrático de Direito. O processo sob um viés mais democratizado não é instrumento para o exercício da jurisdição, monopólio do Estado. O procedimento democrático é uma garantia da efetivação dos direitos constitucionais. A jurisdição migra das "mãos do Estado" para o arcabouço de direitos fundamentais e é assegurada a qualquer cidadão de forma indistinta. E para que isto ocorra, todos os interessados no feito, autor(es), réu(s) e juízes, como é no caso do Tribunal do Júri, devem participar na construção do provimento final.

\footnotetext{
No tribunal do júri o amplo debate jurídico pelos interessados na construção do provimento jurisdicional fica comprometido com a exclusão dos jurados do espaço de argumentação jurídica de construção do provimento. Além disso, o acusado fica à margem da construção participada do provimento, no momento em que os jurados são legitimados a tomarem suas decisões conforme sua consciência e seu senso de justiça. (COSTA, 2012, p. 149).
}

O processo penal deve ter seus procedimentos bem delimitados, deve ser democrático e proporcionar a devida segurança jurídica. Todavia, há quem afirme sê-lo incompatível com o Estado Democrático de Direito e mesmo sua previsão constitucional como direito fundamental não garantem a este tal status. Com o advento da Lei 13.491 de 2017, que retirou competências de tal Tribunal, as críticas são ainda mais severas, como observar-se-á nos capítulos que seguem.

Passa-se agora, a uma análise detalhada de quando ocorre concurso de competências entre o júri e demais órgãos de jurisdição, seja esta comum ou especial.

\section{III - CONCURSO ENTRE A COMPETÊNCIA DO JÚRI E DEMAIS ÓRGÃOS DE JURISDIÇÃO COMUM E ESPECIAL}

O Código de Processo Penal, em seu artigo 78, inciso I, determina que deverá ser observada a regra de prevalência da competência do tribunal do júri em relação a qualquer 
outro órgão da jurisdição comum, em casos de determinação da competência por conexão ${ }^{2}$ ou continência ${ }^{3}$.

Observa-se que o Tribunal do Júri é competente para julgar crimes dolosos contra vida, tentados ou consumados, bem como delitos que não tenham tal natureza, se lhes forem conexos ou continentes, uma vez que a Constituição da República de 1988 determina a competência mínima do Júri Popular, podendo esta ser estendida (não restringida) através de legislação infraconstitucional. Neste caso é pacífica a prevalência da competência do tribunal do júri sobre a competência dos juízes singulares em casos tais.

Há que se falar em controvérsia, quando ocorrer conflito aparente de competência, em relação ao Tribunal do Júri e a competência originária dos tribunais, em caso de prerrogativa de função. O Supremo Tribunal Federal dirime tal controvérsia com a edição através da súmula vinculante 45 , que estabelece que o tribunal objeto do presente estudo, prevalecerá sobre o foro por prerrogativa de função, também conhecido popularmente como foro privilegiado, quando este for estabelecido unicamente pela Constituição Estadual. Observe que, somente neste caso o Júri popular atrai a competência do julgamento de crime contra a vida. Sendo a prerrogativa de função estabelecida em diploma estadual e Constituição Federal ou lei própria que regule o cargo, será competente o Tribunal a qual a autoridade está subordinada. Um exemplo é um ministro do Tribunal de Contas que cometa crime contra a vida de uma pessoa, juntamente a um cidadão comum. Neste caso, será o ministro julgado perante o STF, haja vista a regra de competência estabelecida da carta constitucional e no código de processo penal, em seu artigo 86, inciso III, e o cidadão comum submetido a júri popular.

Cumpre observar ainda, que a competência do Tribunal do Júri não prevalece em casos de conflito entre foros constitucionalmente competentes. Por exemplo, as infrações de menor potencial ofensivo devem ser julgadas perante os juizados especiais criminais (JECrim), conforme determina o dispositivo 98, I, da CRFB/88. Desta forma, caso um crime

\footnotetext{
${ }^{2}$ Conexão é uma hipótese de modificação de competência prevista no artigo 76 do Código de processo penal. Por esta entende-se como o nexo existente entre duas ou mais infrações quando estas se encontrarem "entrelaçadas por um vínculo que aconselha a junção dos processos, propiciando, assim, ao julgador perfeita visão do quadro probatório e, de consequência, melhor conhecimento dos fatos, de todos os fatos, de molde a poder entregar a prestação jurisdicional com firmeza e justiça" (TOURINHO FILHO, 2005, p.197-198).

${ }^{3}$ Continência "como o próprio nome está a identificar, uma casa está contida na outra, não sendo possível cisão.

Como continência se verifica na hipótese de concurso de pessoas (coautoria e participação) - e aí a causa petendi - e nos casos em que se aplique a regra contida na primeira parte do art. 70 do CP - arts. 73, segunda parte, e 74 - conclui-se que, como o fato é o mesmo (no caso de coautoria e participação) ou a conduta é uma só (é a hipótese do concurso formal), podendo afirmar que a continência está em função da identidade da causa petendi ou da unidade da conduta". (TOURINHO FILHO, 2005, p. 203-204).
} 
de competência do Júri e outro de competência do JECrim sejam cometidos sob mesmas circunstâncias de tempo e lugar, deverá ser bipartido o julgamento, processando cada crime sob sua respectiva competência.

Uma hipótese controvertida, verdadeiramente, refere-se à conexão entre um crime de competência do Júri e outro da Justiça Eleitoral. Existem posicionamentos distintos, sendo os de maior respaldo os seguintes entendimentos: primeira posição, acatada por Tourinho Filho, em que prevaleceria a competência da Justiça Eleitoral, em face da regra prevista no artigo 78, IV, CPP: "no concurso entre a jurisdição comum e a especial, prevalecerá esta". (BRASIL, 1941). Logo, um crime doloso contra a vida praticado em conexão com crimes eleitorais seriam julgados por um juízo eleitoral, como determina o artigo 35, inciso II, do Código Eleitoral. A segunda posição acredita na separação de julgamentos, uma vez que leis infraconstitucionais, como o caso do Código de Processo Penal e do Código Eleitoral, não conseguem determinar o deslocamento de competência de julgamento de crimes contra a vida do Tribunal do Júri. Segue esta posição Fernando Capez.

Existe a regra de união processual, em casos de conexão e continência, e de separação dos processos, como se observou anteriormente. O artigo 79, do Código de Processo Penal traz os demais casos de separação, importando para o presente estudo, a questão de concurso entre jurisdição comum e militar.

\section{IV - LEI 13.491/2017: A AMPLIAÇÃO DE COMPETENCIA DA JUSTIÇA CASTRENSE, UMA QUESTÃO DE GARANTIAS FUNDAMENTAIS E RETROCESSO}

Até outubro de 2017, quando surgia o conflito de jurisdições entre o Tribunal do Júri e a Justiça Militar, deveriam ser observadas determinadas circunstâncias para resolver a questão. Esta hipótese, abrange não só o concurso de crimes comuns e militares, mas também o concurso de agentes no mesmo crime, sendo um agente civil e outro militar, determinando neste caso, a separação dos procedimentos. Em regra, o militar seria processado e punido perante a justiça militar, conforme determinam os Códigos Penal e Processual Penal Militar, enquanto o civil, será processado perante a justiça comum, em cometimento de crimes comuns.

O militar que comete um crime doloso contra a vida de outro militar, responde perante a justiça militar, e esta regra permanece inalterada. Quanto ao cometimento de crime doloso contra a vida de civil, praticado por militar, antes do advento da Lei 13.491 de 2017, o militar 
(fosse este estadual ou pertencente às Forças Armadas) teria seu julgamento, excepcionando a regra de competência da justiça castrense, perante a Justiça Comum (Tribunal do Júri), tendo em vista os termos da Lei 9.299 de 1996, que alterou o disposto no artigo 82, §2 do Código de Processo Penal Militar.

Ocorre que, em outubro de 2017, esta competência de julgamento se alterou, ao menos em parte, quanto ao julgamento de militares integrantes das Forças Armadas que cometam crime doloso contra a vida de civis. A Lei 13.491, que modificou a redação do artigo 9 o do Decreto-Lei no 1.001, de 21 de outubro de 1969 - Código Penal Militar -, atribui à Justiça Militar da União a competência para o julgamento de integrantes da marinha, exército ou aeronáutica, caso cometam crimes dolosos, tentados ou consumados, contra a vida de civis, observadas algumas circunstancias. O artigo, passou a ter a seguinte redação:

Art. $9^{\circ} . \S 1^{\circ}$ Os crimes de que trata este artigo, quando dolosos contra a vida e cometidos por militares contra civil, serão da competência do Tribunal do Júri. $\S 2^{\circ}$ Os crimes de que trata este artigo, quando dolosos contra a vida e cometidos por militares das Forças Armadas contra civil, serão da competência da Justiça Militar da União, se praticados no contexto. (Incluído pela Lei $\mathrm{n}^{\circ} 13.491$, de 2017). (BRASIL, 2017, Grifo nosso).

Observe que a competência para julgamento de crimes dolosos contra a vida, praticados por militares, sem serem integrantes das Forças, manteve-se atrelada ao Tribunal do Júri, quando praticados contra civis. Todavia, a competência para o julgamento de crimes dolosos contra a vida, praticados por militares federias fora deslocada para a Justiça Militar da União, não sendo mais subordinada ao Júri Popular, como já mencionado.

A lei 13.491/2017 ampliou a competência da Justiça Militar Federal. Esta promulgação segue na contramão da tendência de esvaziamento das justiças militares, como afirma Lópes Jr. (2017).

Há décadas a jurisprudência consagrou que não basta ser crime militar, praticado por militar e em alguma das situações do artigo $9^{\circ}$ do CPM, é preciso que exista a "efetiva violação de dever militar ou afetação direta de bens jurídicos das forças armadas" ou uma "situação de interesse militar". Nessa mesma perspectiva, em 1996, a Lei 9.296 — posteriormente incorporada no artigo 125 , parágrafo $4^{\circ}$ da Constituição - , atendendo a um reclame de organismos nacionais e internacionais de defesa de direitos humanos, altera o CPM para que os crimes dolosos contra a vida cometidos por militares contra civis fossem julgados pelo tribunal do júri. (LÓPES JR, 2017, p.1). 
Esta nova lei diferencia o militar estadual do militar membro das forças armadas. Assim, esta nova lei, modifica, somente, a situação jurídica dos militares do Exército, Marinha e Aeronáutica, nas situações elencadas no artigo $9^{\circ}$, §2 , do CPM, com redação dada pela Lei 13.491/2017. Observe:

$\S 2^{\circ}$ Os crimes de que trata este artigo, quando dolosos contra a vida e cometidos por
militares das Forças Armadas contra civil, serão da competência da Justiça Militar
da União, se praticados no contexto:
I - do cumprimento de atribuições que lhes forem estabelecidas pelo Presidente da
República ou pelo Ministro de Estado da Defesa;
II - de ação que envolva a segurança de instituição militar ou de missão militar,
mesmo que não beligerante; ou
III - de atividade de natureza militar, de operação de paz, de garantia da lei e da
ordem ou de atribuição subsidiária, realizadas em conformidade com o disposto no
art. 142 da Constituição Federal e na forma dos seguintes diplomas legais: [...].
(BRASIL, 1969, grifo nosso).

Nestas "missões de garantia da lei e da ordem”, conhecidas através da mídia como "ocupações" e nas "outros missões de segurança pública", caso um militar, pertencente a uma das forças elencadas no artigo 142 da CRFB/88, cometa crime doloso contra a vida, será julgado pela Justiça Militar da União, como já observado.

\begin{abstract}
É verdade que parte da doutrina e inclusive da jurisprudência do STM já sustentava que a competência do júri só se aplicaria à Justiça Militar estadual, fazendo uma leitura literal e restritiva do artigo 125 , parágrafo $4^{\circ}$ da Constituição. Contudo, também é verdade que esse desvio de função das Forças Armadas, para exercerem um policiamento urbano "a la carte", é algo novo, posterior à mudança do texto constitucional. A aplicação por analogia (ou interpretação extensiva se preferir) do artigo 125, parágrafo $4^{\circ}$ da $\mathrm{CF}$ aos militares das Forças Armadas, diante dessa nova situação, também seria plenamente sustentável. (LÓPES JR. 2017, p. 1).
\end{abstract}

A nova lei possui diversos pontos controversos, a começar pelo conceito amplo de operações de garantia da lei e da ordem, sendo encarada nos ditames de Aury Lópes Jr. (2017) como "cláusula genérica, vaga e imprecisa". Outro problema trazido pela lei é a distinção, explicita, entre militares que agem em situações análogas. Após 16 de fevereiro de 2018, em que o Presidente da República Michel Temer atuou de ofício e editou o decreto de intervenção federal no estado do Rio de Janeiro, percebeu-se uma tendência beligerante do Estado, e as Forças Armadas são, cada vez mais, convocadas para tentar resolver o problema, da segurança pública, instaurado no Brasil. Neste contexto, policiais militares (militares estaduais), responsáveis pelo policiamento ostensivo, atuam frequentemente em conjunto a membros das Forças Armadas (militares federais). A grande questão perfaz numa hipótese de 
ação, em idêntica situação, promovida por estas duas classes numa operação para a garantia da lei e da ordem em alguma comunidade. Na hipótese de um membro das Forças Armadas, em concurso com um policial militar, cometer um crime doloso contra a vida de um civil, em uma abordagem, não haverá igualdade de tratamento processual, à medida que o militar federal será julgado perante a Justiça Militar Federal, enquanto o militar estadual será julgado perante o Tribunal do Júri. Observa-se aqui a aberração legislativa trazida pela nova lei. Mesmo em situações análogas, o tratamento é diferenciado. Seria considerável a hipótese de tratamento diferente, caso as classes supramencionadas agissem em situações diversas, devendo ser ofertado ao militar federal tratamento específico em caso de ação que acarretasse em crime doloso contra a vida de civil.

A tendência observada nesta lei é, como mencionado anteriormente, a militarização da segurança pública. Esta que é papel do Estado, direito e responsabilidade de todos, conforme o artigo 144 da CRFB/88, deve ser exercida através da polícia federal, polícia rodoviária (e ferroviária) federal, policias civis, polícias militares e corpos de bombeiros militares, e não (pelo menos rotineiramente) através das Forças Armadas. Todavia, percebe-se a convocação do Exército, Marinha e Aeronáutica com certa frequência para exercer o papel de polícia administrativa, através do policiamento ostensivo e repressor, o que desvia, por completo, a essência destas instituições.

\footnotetext{
Armadas em verdadeiro desvio de função, numa tentativa desesperada da União (e dos estados que solicitam) de enfrentar a violência urbana crescente (que, como se sabe, decorre de fatores complexos em que, além da repressão, é imprescindível uma anamnese séria das causas), especialmente por causa de uma política antidrogas que se mostra equivocada. (LÓPES JR., 2017, p.1).
}

Esta Lei é o oposto do que se percebe, em tratamento legislativo, referente aos Tribunais Militares, que têm suas competências cada vez mais restritas e adstritas a questões especificamente militares.

[...] os tribunais militares tampouco se justificam em tempo de paz, devendo ter sua atuação realmente limitada aos crimes militares, quando praticados por militares e diante de um real e peculiar interesse militar. Do contrário, é violação do juiz natural. (LÓPES JR., 2017, p. 1).

A Lei 13.491/2017 inovou ainda mais, ao ponto de alterar o inciso II do artigo $9^{\circ}$ do CPM. Agora, a Justiça Militar, seja ela federal ou estadual, será competente para o julgamento dos crimes previstos no Código Penal Militar e nas legislações penais comum e especial 
quando praticados por militares. Antes de outubro de 2017, cabia à Justiça Militar o julgamento dos militares pela prática dos crimes previstos no CPM, não sendo esta competente para o julgamento dos crimes previstos nas leis penais especiais. Assim, um militar que cometesse abuso de autoridade ou tortura, por exemplo, eram julgados pela Justiça comum, a medida que tais crimes não possuíam (e ainda não possuem) previsão no CPM. Mesmo em caso de conexão com crime militar, haveria cisão dos julgamentos. Agora, com a nova redação, a prática de crimes de abuso de autoridade, tortura, e todos os outros não previstos na legislação militar serão julgados pela Justiça castrense. Mais um exemplo de que a Lei 13.491/2017 segue oposta à tendência de esvaziamento da jurisdição militar. Pelo contrário, esta lei amplia, e muito, a competência da Justiça castrense.

\footnotetext{
Já existe, inclusive, quem sustente que os crimes previstos na Lei Maria da Penha, quando praticados por militar, também estariam submetidos à Justiça Militar. Isso, a nosso ver, é um exagero, na medida em que esbarra na absoluta falta de interesse militar, afetação de bens militares ou aderência à atividade militar. (LÓPES JR., 2017, p. 1).
}

A nova lei traz ainda, conforme Lópes Jr. (2017), um "risco de corporativismo", principalmente em crimes que são percebidos e valorados de maneira distinta por policiais e civis, como o caso do abuso de autoridade e tortura. Outro risco refere-se à possibilidade de morosidade de processos perante a Justiça militar, que passará a ser responsável, imediatamente, por diversas demandas, uma vez que a lei processual é imediatamente aplicada a processos em andamento. Cumpre mencionar, ainda, que está superada a Súmula 172 do STJ, que dispunha ser competente a justiça comum para o processamento e julgamento de militar por crime de abuso de autoridade, mesmo que durante serviço, haja vista a perda de sentido do enunciado.

\section{CONCLUSÃO}

O Tribunal do Júri possui competência atribuída pela Constituição da República Federativa do Brasil de 1988 para processar e julgar crimes dolosos contra a vida, na modalidade tentada e consumada. A nova Lei, que alterou o Código Penal Militar marca um retrocesso e uma supervalorização da justiça castrense, ao ponto de seguir em contramão das tendências legislativas alienígenas de esvaziamento desta. 
Neste contexto, o homicídio, em sua forma simples ou qualificada; o induzimento, instigação ou auxílio a suicídio; o aborto e o feminicídio, exemplificando, quando forem cometido ou tentas por militares das Forças Armadas contra civis, serão de competência da Justiça Militar da União, e não mais do Tribunal do Júri, desde que praticados no cumprimento de atribuições estabelecidas pelo Presidente da República ou Ministro de Estado da Defesa, em ações que envolvam a segurança de instituições militares, missões militares, ainda que não beligerantes ou, na mais ampla situação, em operações de paz de garantia de lei e ordem ou de atribuição subsidiária. A referida lei segredou militares federais e estuais, mesmo quando praticam o crime contra à vida em situações análogas.

A Lei 13.491/2017 não só esvaziou a competência do Tribunal do Júri quando do processamento e julgamento de crimes contra a vida praticados por militares federais contra civis, mas também, ampliou a competência da Justiça Militar para o julgamento dos crimes previstos no CPM e nas legislações penais comuns e especiais quando praticados por militares. Por isto afirma-se que a nova lei vai muito além da questão de esvaziamento da competência do júri. Representa sim, uma significativa ampliação das justiça castrense, que agora deverá se equipar para "dar conta" de novas diversas demandas. Este "entulhamento processual" (sim, pois trata a lei de procedimento, e como a lei processual aplica-se imediatamente, possivelmente ocorrerá um "entulhamento" da justiça militar) de certo exigirá investimentos estruturais, tanto nas Justiças militares estaduais e federais como no órgão investigativo militar. Possivelmente, os processos e investigações sofrerão atrasos, uma vez que a justiça castrense não fora criada para tais fins. A morosidade processual irá gerar impactos na vida dos usuários e da própria administração da Justiça, que deverá se adequar.

Outro risco, como já mencionado, é a possibilidade do corporativismo influenciar em julgamentos, especialmente nos crimes de abuso de autoridade, tortura, porte ilegal de armas e outros próprios do ofício. É, ainda provável, que tratamento não corresponda ao que se espera em termos de eficácia, por uma questão de percepção diferenciada da tipicidade e dos limites das causas de exclusão da ilicitude.

De qualquer forma, em termos gerias, a ampliação da competência da justiça castrense representa sim um retrocesso, como já mencionado, além de ser desnecessária e inadequada, tanto em termos econômicos, tanto em termos de evolução democrática. Questiona-se ainda, a modificação da competência do júri por lei infraconstitucional. Quanto à ampliação, não há problemas, mas resta a dúvida, se não seria esta modificação, uma certa forma de restrição de competência. 


\section{REFERENCIAS}

BANDEIRA, Marcos. Tribunal do Júri: De conformidade com a Lei no 11.689, de 09 de junho de 2008 e com a ordem constitucional. Ilhéus: Editus, 2010. http://www.uesc.br/editora/livrosdigitais2015/tribunal_do_juri.pdf

BRASIL. Constituição da República Federativa do Brasil de 1988. Brasília, Distrito Federal, 5 out. 1988. Disponível em:

http://www.planalto.gov.br/ccivil_03/constituicao/constituicaocompilado.htm. Acesso em: 18 set. 2018.

BRASIL. Decreto-Lei n. 1.001, de 21 de outubro de 1969. Código Penal Militar. Brasília, DF, 21 out. 1969. Disponível em:

http://www.planalto.gov.br/ccivil_03/decretolei/Del1001.htm. Acesso em: 19 set. 2018.

BRASIL. Decreto-Lei n. 1.002, de 21 de outubro de 1969. Código de Processo Penal Militar. Brasília, DF, 21 out. 1969. Disponível em: http://www.planalto.gov.br/ccivil_03/decreto-lei/Del1002.htm. Acesso em: 19 set. 2018.

BRASIL. Decreto-Lei n. 2.848, de 7 de dezembro de 1940. Código Penal. Rio de Janeiro, 7 dez. 1940. Disponível em:

http://www.planalto.gov.br/ccivil_03/decretolei/Del2848compilado.htm. Acesso em: 18 set. 2018.

BRASIL. Decreto-Lei n. 3.689, de 3 de outubro de 1941. Código de Processo Penal. Rio de Janeiro, 3 out. 1941. Disponível em:

http://www.planalto.gov.br/ccivil_03/DecretoLei/Del3689.htm. Acesso em: 18 set. 2018.

BRASIL. Lei n. 4.737, de 15 de julho de 1965. Institui o Código Eleitoral. Brasília, DF, 15 jul. 1961. Disponível em: http://www.planalto.gov.br/ccivil_03/leis/L4737.htm. Acesso em: 19 set. 2018.

BRASIL. Lei n. 9.299, de 7 de agosto de 1996. Altera dispositivos dos Decretos-leis $\mathbf{n}^{\circ} \mathbf{s}$ 1.001 e 1.002, de 21 de outubro de 1969, Códigos Penal Militar e de Processo Penal Militar, respectivamente. Brasília, DF, 7 ago. 1996. Disponível em:

http://www.planalto.gov.br/ccivil_03/LEIS/L9299.htm. Acesso em: 19 set. 2018.

BRASIL. Lei n. 13.491, de 13 de outubro de 2017. Altera o Decreto Lei n. 1.001, de 21 de outubro de 1969 - Código Penal Militar. Brasília, DF, 9 out. 2017. Disponível em:

http://www.planalto.gov.br/ccivil_03/_ato2015-2018/2017/lei/L13491.htm. Acesso em: 10 set. 2018.

CAPEZ, Fernando. Curso De Processo Penal. 25 ed. São Paulo: Saraiva, 2018.

COSTA, Fabrício Veiga. O mito, a linguagem e o discurso no tribunal do Júri. Revista Eletrônica do Ministério Público do Estado de Goiás, n. 1, p. 123-162, out./dez. 2011. 
Disponível em:

http://www.mp.go.gov.br/revista/pdfs_1/O\%20mito,\%20a\%20linguagem\%20e\%20o\%20disc urso\%20no\%20tribunal\%20do\%20juri.pdf. Acesso em: 05 set. 2018.

LÓPES JR. Aury. Lei 13.491/2017 fez muito mais do que retirar os militares do tribunal do júri. Consulto Jurídico. Disponível em: https://www.conjur.com.br/2017-out-20/limitepenallei-134912017-fez-retirar-militares-tribunal-juri. Acesso em: 18 set. 2018.

LÓPES JR. Aury. Tribunal do júri precisa passar por uma reengenharia processual.

Consultor Jurídico. Disponível em: https://www.conjur.com.br/2014-ago-08/limitepenaltribunal-juri-passar-reengenharia-processual. Acesso em: 18 set. 2018.

OLIVEIRA, Laís Mendes. Tribunal do Júri e o Subjetivismo Inquisitivo. De Jure, Belho Horizonte. v. 16, n. 28, p. 235-254, jan./jun. 2017.

https://aplicacao.mpmg.mp.br/xmlui/bitstream/handle/123456789/1326/Tribunal\%20do\%20J uri.pdf?sequence $=1$.

STF. Súmula Vinculante 45. Disponível em:

http://www.stf.jus.br/portal/jurisprudencia/menuSumario.asp?sumula=2362. Acesso em: 18 set. 2018.

TOURINHO FILHO, Fernando da Costa. Código de processo penal comentado. 13. ed., rev. e atual. São Paulo: Saraiva, 2010.

TOURINHO FILHO, Fernando da Costa. Processo Penal. 27 ed. São Paulo: Saraiva, 2005. 